\title{
Mechanical Extraction and Physical Characterization of Pandanus Odorifer Lignocellulosic Fibre
}

\author{
M. D. Teli ${ }^{1}$, A. C. Jadhav ${ }^{2}$ \\ ${ }^{1}$ Professor, Dept. of Fibres and Textile Processing Technology, Institute of chemical Technology, Mumbai, Maharashtra, India \\ ${ }^{2} \mathrm{Ph} . \mathrm{D}$ (Scholar), Dept. of Fibres and Textile Processing Technology, Institute of chemical Technology, Mumbai, Maharashtra, India
}

\begin{abstract}
Lignocellulosic fibres have been investigated to understand its influence on properties of textile fibres. Pandanus Odorifer (PO) is a leaf fibre which was mechanically extracted from the leaves of the plant using water retting extraction method. The chemical composition of the extracted fibres was determined using TAPPI method. The composition mainly consisted of cellulose $44 \pm 1 \%$, hemicelluloses $30 \pm 1 \%$, lignin $21 \pm 1 \%$, ash content $2.5 \pm 0.5 \%$, and extractives around $2.5 \pm 0.5 \%$, Structural analysis was carried out by FTIR, SEM, TGA, X-ray diffraction. Tensile and moisture content properties were also studied.
\end{abstract}

Keywords: Pandanus Odorifer fibres, retting, fibre extraction, chemical composition, structural analysis.

\section{Introduction}

Natural fibre has been used since prehistoric times. There are at least 1000 types of plants that bear usable fibres [1]. Natural plant fibres are easily obtained in many tropical parts and are available throughout the world. Today these fibres are considered as environment friendly materials owing to their biodegradability and renewable properties [2]. Natural fibres have applications in fields of textile, paper manufacturing, and bioenergy industries owing to their broad availability and properties. Natural fibres can generally be classified based on their origin (e.g., plant, animal, or mineral). Plant/vegetable fibres can be further classified into subgroups according to their source (e.g., stem fibres, leaf fibres, seed fibres, or fruit fibres) [3, 4]. Natural fibres that are obtained from different parts of the plants, to name few, for e.g. jute, ramie, flax, kenaf and hemp are obtained from the stem; sisal, banana and pineapple from the leaf; cotton and kapok from seed; coir from the fruit.

All plant species are built up of cells. When a cell is very long in relation to its width it is called a fibre. The components of natural fibres are cellulose, hemicellulose, lignin, pectin, waxes and water-soluble substances. The cellulose, hemicellulose and lignin are the basic components of natural fibres, governing the physical properties of the fibres. Cellulose is a semi-crystalline polysaccharide and is responsible for the hydrophilic nature of natural fibres. Hemicellulose is a fully amorphous polysaccharide with a lower molecular weight compared to cellulose. The amorphous nature of hemicelluloses results in it being partially soluble in water and alkaline solutions. Pectin, whose function is to hold the fibre together, is a polysaccharide like cellulose and hemicellulose. Lignin is an amorphous polymer but unlike hemicellulose, lignin is comprised mainly of aromatics and has little effect on water absorption. The chemical composition of plant fibres plays an important role. The composition depends on the type, age, and origin of the fibre, as well as the method of fibre extraction. The properties of natural fibres also depend on their chemical composition [5-7]. Over 100 million tons of different synthetic fibres are manufactured every year out of which more than $50 \%$ of that is derived from crude oil [8].Therefore, many efforts are made to replace at least a small portion of synthetic fibres with cellulose fibres which are obtained from plants or agro-waste materials. Day by day awareness is increasing in Consumers about environmentally friendly products and more and more people want to buy it [9]. In recent years there has been a growing interest of various industries in renewable plant materials. So far, various plants are used for the production of cellulose based fibres, such as cotton, hemp, agave, flax, kapok, sisal, ramie and hemp. Recently studies have been carried out on agrowaste materials to obtain natural cellulose fibres from wheat straw, soyabean straw, rice straw, corn stalks leaves and stalks of sorghum, banana leaves, sugar cane [10-16]. Advantages of natural fibres over man-made fibres include low density, low cost, recyclability and biodegradablility [17-19]. So various attempts are being made to use annually renewable lignocellulosic agricultural by products.

Pandanus odorifer is an aromatic monocot species of plant in the Pandanaceae family, native to Polynesia, Australia, South Asia (Andaman Islands), and the Philippines and is also found in the wild in southern India and Burma. It is commonly known as screw-pine. It is a small branched, palm-like dioecious tree with a flexuous trunk supported by brace roots. The tree can grow to a height of 4 meters. Leaves grow in clusters at the branch tips, with rosettes of sword-shaped, stiff and spiny bluish-green, fragrant leaves. Leaves are glaucous, $40-70 \mathrm{~cm}$. long. In summer, the tree bears very fragrant flowers [15]. Aromatic oil (kevda oil) and fragrant distillate (otto) called keorra-ka-arak are extracted from the male flowers. They are almost exclusively used in the form of a watery distillate called kewra water. It is also called as Kevda plant in India. So an attempt has been made here to investigate the properties of PO fibres and to explore its further potential to be used as textile as well as composite material.

In the present work, an attempt has been made to investigate 


\section{International Journal of Science and Research (IJSR) \\ ISSN (Online): 2319-7064}

Index Copernicus Value (2015): 78.96 | Impact Factor (2015): 6.391

the properties of Pandanus Odorifer (PO) leaf fibres and to explore its further potential to be used as textile material, as this plant is widely used for its medicinal properties overall. The characterization of the fibres was carried out by using advanced techniques like FTIR, XRD and TGA has been done and its chemical composition is estimated. The surface is examined using (SEM) scanning electron microscope and mechanical properties of the fibres are also evaluated.

\section{Experimental}

\subsection{Materials}

The fibre was extracted from the leaves of the Pandanus odorifer (PO) plant which was collected from Wadala, (Mumbai, India). The PO fibres were used without any pretreatment or purification. The chemical reagents of analytical grade such as sodium chlorite, glacial acetic acid, sodium hydroxide, sulphuric acid, ethanol, toluene and acetone were procured from SD Fine Chemicals Ltd., India.

\subsection{Methods}

\subsubsection{Fibre extraction}

The fibres were extracted from the leaves of the Pandanus odorifer plant. The leaves of Pandanus Odorifer are around 1-1.5 $\mathrm{m}$ in length. These leaves have sharp and spiny thorns on the edges of the leaves and in the middle of the leaf; so first the thorns were removed with the help of the knife. After the removal of thorns the leaves were kept for water retting for 10 days. After retting the leaves were boiled for 2 hrs which helped in pulling out the fibre easily. These fibres were washed in running water and were sun dried, combed and hand brushed to get uniform fibre and make them suitable for physical, chemical and morphological analysis.

\subsubsection{Determination of chemical composition}

The chemical composition of the PO raw fibre was determined as follows: the dewaxing of the fibre was carried out by boiling the fibre in a mixture of toluene/ethanol (1:1 $\mathrm{v} / \mathrm{v}$ ) in a soxhlet apparatus for $6 \mathrm{~h}$. The de-waxed fibres were then filtered, washed with ethanol, and dried. The percentage of holocellulose was calculated according to the method described previously [18]. In this method, the extracted residue of de-waxed fibre was boiled in a mixture of $\mathrm{NaClO}_{2}$ and acetic acid for $4 \mathrm{~h}$. The suspension was cooled in an ice bath for some time, filtered, and washed with cold distilled water. Finally, it was washed with acetone and dried. The acid-insoluble lignin content was determined according to TAPPI T222 om-02 (2002). In this method of determination, lignin (also known as "Klasons lignin") is defined as constituents fibre insoluble in $72 \%$ sulphuric acid. The $\alpha$ cellulose content was determined by TAPPI T203 cm-99 (2002). Ash content was determined by standard method of TAPPI T211 om-02 (2002). In this method pre-weighed fibre sample was subjected to $525{ }^{\circ} \mathrm{C}$ in a muffle furnace [19].

\subsubsection{Morphological studies}

The scanning electron micrographs of the fibre surface were recorded on a (JSM 6380LA JEOL, Japan), from Institute of Chemical Technology. The fibre samples were sputter coated with gold before recording the micrographs.

\subsubsection{FTIR analysis}

The IR spectra of raw PO fibre sample was recorded using FTIR spectrophotometer (Shimadzu 8400s, Japan) using ATR sampling technique by recording 45 scans in $\%$ transmittance mode in the range of $4000-600 \mathrm{~cm}^{-1}$.

\subsubsection{X-ray Diffraction (XRD)}

The crystallinity of raw PO fibre was studied using an X-ray diffractometer (Shimadzu 6100, Japan) equipped with $\mathrm{CuK}_{\alpha}$ radiation $\left(\lambda=1.54{ }^{\circ} \mathrm{A}\right)$ in the $2 \theta$ range $2-50^{\circ}$. The experiment was performed in the reflection mode at a scan speed of $2^{\circ} /$ min in steps of $0.02^{\circ}$. The crystallinity index (CrI) of the fibre was calculated according to the Segal empirical method given below in equation. 1 [20].

$$
\mathrm{CrI} \%=\left(\mathrm{I}_{002}-\mathrm{I}_{\mathrm{am}}\right) \times 100 / \mathrm{I}_{002}
$$

Where $I_{002}$ and $I_{a m}$ are the peak intensities of crystalline and amorphous materials, respectively.

\subsubsection{Thermal analysis}

A sample of PO fibre was cut into small pieces and thermal gravimetric analysis (TGA) was carried out. The thermograms were recorded on Shimadzu $60 \mathrm{H}$ DTG machine using aluminium pan between temperature range $30-500{ }^{\circ} \mathrm{C}$ under the inert atmosphere of nitrogen at a flow rate of $50 \mathrm{ml} / \mathrm{min}$.

\subsubsection{Tensile properties and Moisture regain}

The tensile properties of the fibre were measured in terms of the breaking load, percentage elongation at breaking using Tinius Olsen tensile testing machine. A gauge length of 20 $\mathrm{mm}$ with a speed of $5 \mathrm{~mm} / \mathrm{min}$ was used for the testing. Approximately 15 fibres were tested for their tensile properties. To identify the moisture content and moisture regain values, the fibre sample was tested according to ASTM standard method 2495.

\section{Results and Discussion}

\subsection{Determination of Fibre composition}

The chemical composition of PO fibre by mechanical extraction method is reported in the Table. 1. The raw fibre is composed of cellulose, hemicelluloses, lignin, ash and extractives.

Table 1: Chemical Composition of PO fibre

\begin{tabular}{|c|c|c|c|c|c|}
\hline Sample & $\begin{array}{c}\alpha- \\
\text { Cellulose } \\
(\%)\end{array}$ & $\begin{array}{c}\text { Hemi- } \\
\text { cellulose } \\
(\%)\end{array}$ & $\begin{array}{c}\text { Lignin } \\
(\%)\end{array}$ & $\begin{array}{c}\text { Ash } \\
(\%)\end{array}$ & $\begin{array}{c}\text { Extractive } \\
(\%)\end{array}$ \\
\hline PO fibre & $44 \pm 1$ & $30 \pm 1$ & $21 \pm 1$ & $2.5 \pm 0.5$ & $2.5 \pm 0.5$ \\
\hline
\end{tabular}

\subsection{Morphological studies}

Scanning electron microscopy (SEM) showed the influence on PO fibre morphology which was mechanically extracted fig.2 (a-b). Like other lignocelluloses fibre PO fibre obtained by mechanical extraction process have a thick layer of deposits on the fibre surface which mainly composed of wax, lignin, pectin and hemicellulose, which protect cellulose fibre inside [21]. 


\section{International Journal of Science and Research (IJSR) \\ ISSN (Online): 2319-7064}

Index Copernicus Value (2015): 78.96 | Impact Factor (2015): 6.391

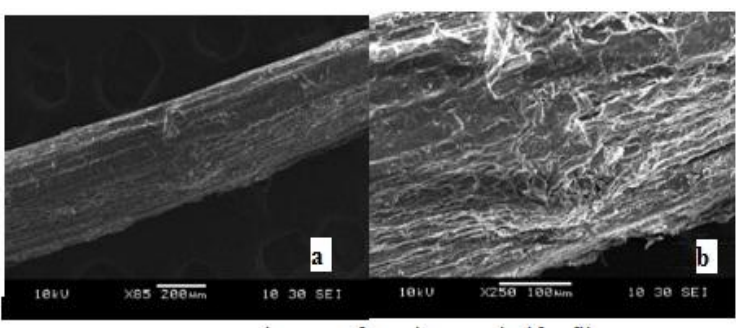

Figure 2: SEM images of $\mathrm{PO}$ fibre

\subsection{FTIR analysis}

The FTIR spectra of the raw PO fibre is presented in fig 3. The spectra exhibited a broad band in the region of 3400 to $3300 \mathrm{~cm}^{-1}$ are asssigned to the adsorbed water which indicates the free $\mathrm{O}-\mathrm{H}$ stretching vibration of the $\mathrm{OH}$ group in cellulose molecules. A peak at $1726 \mathrm{~cm}^{-1}$ for attributed to the $\mathrm{C}=\mathrm{O}$ stretching vibration of the acetyl and uronic ester groups, from pectin, hemicelluloses, or the ester linkage of the carboxylic group of ferulic and p-coumaric acids of lignin and/or hemicellulose [22, 23]. The absorption peak was absorbed at $1623 \mathrm{~cm}^{-1}$ which reflect the stretching of the $\mathrm{O}-\mathrm{H}$ group. The absorption peak at $1238 \mathrm{~cm}^{-1}$ in the raw fibre is attributed to the $\mathrm{C}-\mathrm{O}$ out of plane stretching vibration of the acetyl group in the lignin [24]. The peak at $896 \mathrm{~cm}^{-1}$ attributes $\mathrm{C}-\mathrm{H}$ rocking vibrations assigned to $\beta$-glucosidic linkage. Similarly the peaks at 1421,1369 and $1317 \mathrm{~cm}^{-1}$ present in raw fibre are associated with the bending vibrations of $-\mathrm{CH}_{2}, \mathrm{C}-\mathrm{H}$, and $\mathrm{C}-\mathrm{O}$ of cellulose $[25,26]$. Similarly the peak at $1020 \mathrm{~cm}^{-1}$ assigned to aromatic $\mathrm{C}-\mathrm{H}$ in plane deformation and a peak at $1157 \mathrm{~cm}^{-1} \mathrm{C}-\mathrm{O}-\mathrm{C}$ asymmetrical stretching in cellulose and hemicellulose.

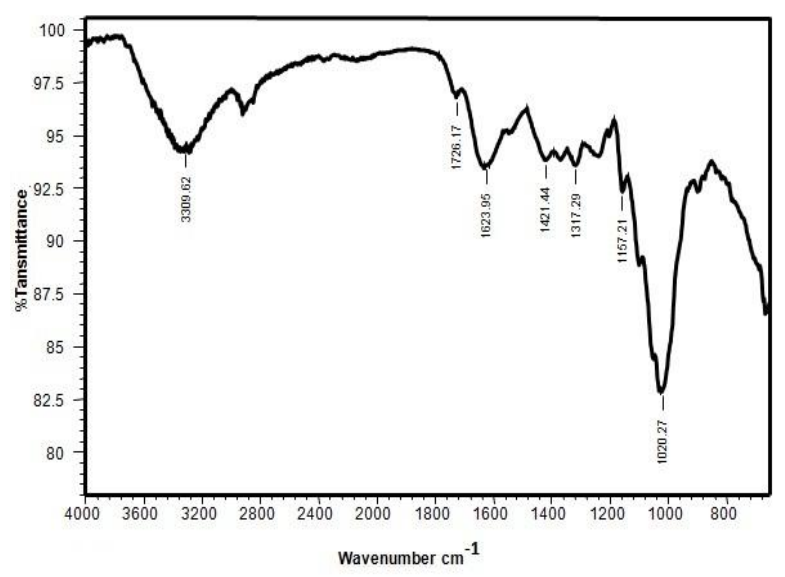

Figure 3: FTIR spectra of raw PO fibre

\subsection{XRD analysis}

The X-Ray diffraction pattern of raw fibre is shown in Fig 4. The diffractogram showed two reflections, corresponding to $2 \theta$ values of around $16^{\circ}$ and $22.5^{\circ}$ respectively. Among these, the low angle reflection $\left(16^{\circ}\right)$ was of low intensity, representing $\mathrm{I}_{(\mathrm{am})}$ of amorphous material and the other reflection $\left(22.5^{\circ}\right)$ had higher intensity, and it represented $\mathrm{I}_{(002)}$ of crystalline material in cellulosic fibre. The degree of crystallinity (CrI\%) was calculated using Eq. (1). Crystallinity index of PO fibre is described below in Table 2.

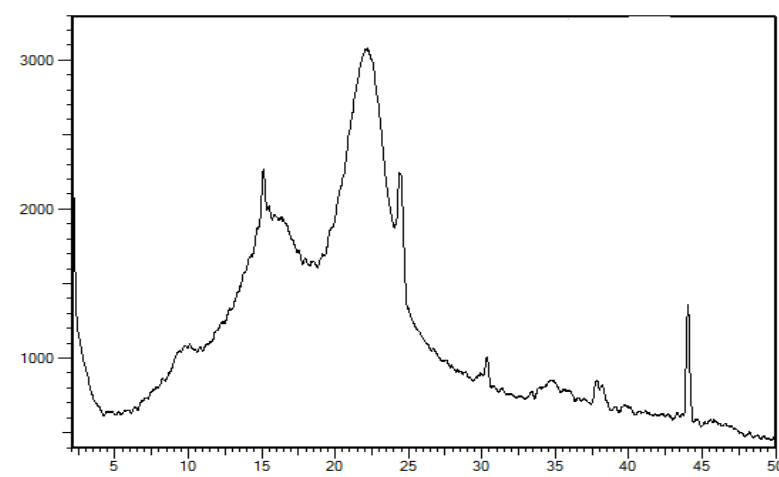

Figure 4: X'RD diffraction pattern of PO fibre

Table 2: Crystallinity Index of PO fibre

\begin{tabular}{|l|c|c|c|}
\hline Sample & $\begin{array}{c}\mathrm{I}(\mathrm{am}) \text { at } 2 \Theta \\
15.5^{\circ}\end{array}$ & $\begin{array}{c}\mathrm{I}(002) \text { at } 2 \Theta \\
22^{\circ}\end{array}$ & $\mathrm{CrI} \%$ \\
\hline PO fibre & 318 & 588 & 46.01 \\
\hline
\end{tabular}

\subsection{TGA analysis}

The thermogram of PO fibre is shown in Fig.5. and it can be observed that the thermal degradation of PO fibre exhibited a three - step process. Yang et al. attributed this behaviour to the differences in the chemical structures, of different components of wood fibre which decompose at different temperatures [27].

PO fibre being lignocellulosic material is a composite structure of different types of components, and it will degrade below 400 ${ }^{\circ} \mathrm{C}$ with wax, pectin, and hemicelluloses degraded at $180{ }^{\circ} \mathrm{C}$, cellulose at around $300{ }^{\circ} \mathrm{C}$, and lignin at $400{ }^{\circ} \mathrm{C}$ [28].

The first, second and third stages of decomposition were found in the temperature ranges of $30-120{ }^{\circ} \mathrm{C}, 200-270{ }^{\circ} \mathrm{C}$ and $270-$ $400{ }^{\circ} \mathrm{C}$ respectively. The first decomposition temperature range of $30-120^{\circ} \mathrm{C}$ corresponded to the evaporation of moisture and weight loss was $9.72 \%$. The second decomposition step of raw fibre in the temperature range of $200-270{ }^{\circ} \mathrm{C}$ indicated the loss of hemicellulose and some part of the lignin taking the weight loss to $15.53 \%$. The third degradation step corresponding to the degradation of cellulose was observed in the range of 270-400 ${ }^{\circ} \mathrm{C}$ causing maximum weight loss of 53.52\%. Similar observation was also made in many other natural fibres $[29,30]$. Since the fibre had very good thermal stability upto $270{ }^{\circ} \mathrm{C}$, it does have potential to be used as textile material and thus will have a large applicability in various sectors of technical or smart textiles.

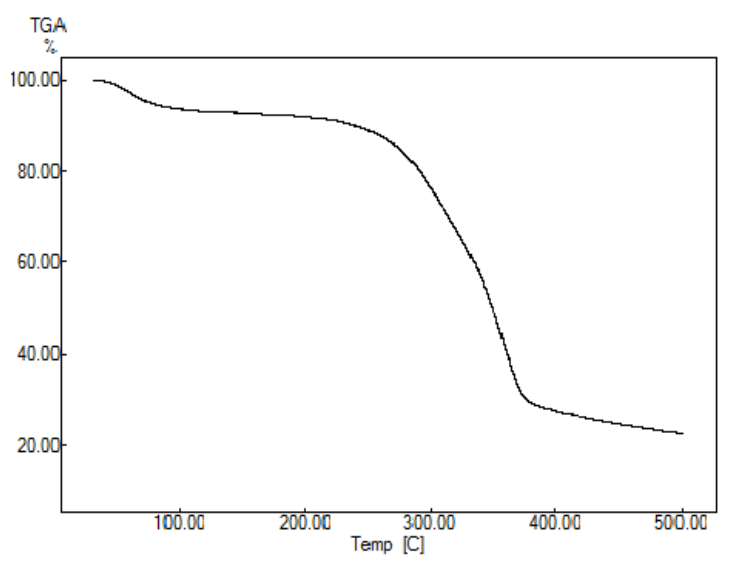

Figure 5: Thermogram of raw PO fibre 


\section{International Journal of Science and Research (IJSR) \\ ISSN (Online): 2319-7064}

Index Copernicus Value (2015): 78.96 | Impact Factor (2015): 6.391

\subsection{Tensile properties and moisture regain}

The fibre showed good fibre tensile properties exhibiting $572.1 \mathrm{gf}$ with elongation at break $4.81 \%$ and moisture content of $9.72 \%$.

\section{Conclusion}

The natural lignocellulosic fibre which was mechanically extracted from Pandanus Odorifer plant has cellulose content around 44\% enabling it to be suitable for the textile applications. The XRD analysis showed that the fibres have a crystallinity of $46 \%$ which is similar to most of the natural fibres available. TGA analysis showed that the fibre had a very good thermal stability upto $270^{\circ} \mathrm{C}$. The tensile strength was also good. These properties show that, the fibre has a great potential to be used as a textile material. Although this plant is mostly grown in wild, if this fibre gets commercialized then there is likely hood that the farmers can also get a new source of income by growing this plant on a large scale, as it requires very less maintenance and it is easy to grow. The properties of the Pandanus Odorifer fibres make them suitable for advanced textile applications and hence show promising potential.

\section{References}

[1] Robson, J.; Hague, J.; Newman, G.; Jeronimidis, G.; Ansell, M. P. Report No. EC/431/92 to DTI LINK Structural Composites Committee, January 1993.

[2] Varma, I.K., Ananthakrishnan, S.R. \& Krishnamoorthi, S. (1989). Composite of glass/modified jute fabric and unsaturated polyester. Composites; 20:383.

[3] Reddy, N., \& Yang, Y. (2009). Properties of natural cellulose fibres from hop stems. Carbohydrate Polymers, 77(4), 898-902

[4] Wambua, P., Ivens, J., \& Verpoest, I. (2003). Natural fibres: Can they replace glass in fibre reinforced plastics? Composites Science and Technology, 63(9), 1259-1264.

[5] Bledzki, A. K., \& Gassan, J. (1999). Composites reinforced with cellulose based fibres. Progress in Polymer Science, 24, 221-274.

[6] Saheb, D. N., Jog, J. P., Natural Fibre Polymer Composites: A Review, Advances in Polymer Technology, 1999, 18 (4), 351-363.

[7] Li, X., Tabil, T. G., Panigrahi, S., Chemical Treatments of Natural Fibre for Use in Natural Fibre-Reinforced Composites: A Review, Journal of Polymers and the Environment, 2007, 15, 25-33.

[8] Huda, S., Reddy, N., Karst, D., Xu, W., Yang W, Yang Y. Non-traditional biofibres for a new textile industry. J. Biobased Mater. Bioenergy 2007; 1 (2): 177-190.

[9] Fibre Futures is a sustainable future; http://www.sustainable- future.org/ future fibres/solutions.html

[10]Reddy, N., Yang, Y., (2007). Preparation and characterization of long natural cellulose fibres from wheat straw. J. Agric. Food Chem.; 55; 21: 8570-8575.

[11]Reddy, N., Yang, Y., (2009) Natural cellulose fibres from soybean straw. Bioresource Technology, 100 3593-3598
[12] Chen, X., Yu, J., Zhang, Z., Lu, C., (2011). Study on structure and thermal stability properties of cellulose fibres from rice straw. Carbohydrate Polymers; 85; 1 : 245-250.

[13] Reddy N, Yang Y. Structure and properties of high quality natural cellulose fibres from cornstalks; Polymer 2005; 46: 5494-5500.

[14] Reddy N, Yang Y. Structure and properties of natural cellulose fibres obtained from sorghum leaves and stems; J. Agric. Food Chem. 2007; 55; 14: 5569- 5574.

[15] Sinha, M.K., The use of banana-plant fibre as a substitute for jute. J. Textile Inst. 1974; 65; 27: 27-33.

[16] Costa, S.M., Mazzola, P.G., Silva, J.C.A.R., Pahl, R., Pessoa, Jr. A, Costa, S.A., (2013). Use of sugar cane straw as a source of cellulose for textile fibre production. Industrial Crops and Products, 42: 189-194.

[17] Mohanty, A.K., Wibowo, A., Misra, M, Drzal L.T., (2003).Composite part A: Applied Science and Manufacturing 35:363

[18] Wise, L.E., Murphy, M., and D'Addieco, A. A. (1946). "Chlorite, holocellulose, its fractionation and bearing on summative wood analysis and on studies on the hemicelluloses," Paper Journal 122(2), 35-43.

[19] Teli, M.D, and Jadhav, A.C., (2016) Extraction and Characterization of Novel Lignocellulosic Fibre. Journal of Bionanoscience, 10(5), 418-423(6).

[20] Segal, L., Creely, J. J., Martin, A. E., and Conrad, C. M. (1959). "An empirical method for estimating the degree of crystallinity of native cellulose using the X-ray diffractometer," Textile Research Journal 29(10), 786794.

[21] Teli, M.D, and Jadhav, A.C., (2016). Effect of alkali treatment on the properties of Agave augustifolia v. marginata fibre. International Research Journal of Engineering and Technology (IRJET). 3(5), 2754-2761.

[22] Sain, M., and Panthapulakkal, S. (2006). "Bioprocess preparation of wheat straw fibre and their characterization," Industrial Crops and Products 23(1), $1-8$.

[23] Sun, X. F., Xu, F., Sun, R. C., Fowler, P., and Baird, M. S. (2005). "Characteristics of degraded cellulose obtained from steam-exploded wheat straw," Carbohydrate Research 340(1), 97-106.

[24] Troedec, M., Sedan, D., Peyratout, C., Bonnet, J., Smith, A., and Guinebretiere, R. (2008). "Influence of various chemical treatments on the composition and structure of hemp fibres," Composites Part A - Applied Science and Manufacturing 39(3), 514-522.

[25]Alemdar, A., and Sain, M. (2008). Isolation and characterization of nano fibres from agricultural residues - Wheat straw and soy hulls, Bioresource Technology 99(6), 1664-1671.

[26] Teli, M.D., and Jadhav, A.C., (2015) Effect of alkalization on the properties of Abelmoschus Manihot lignocellulosic fibre. International Journal of Current Engineering and Technology, 5(6), 2277-4106.

[27] Yang, H., Yan, R., Chen, H., Lee, D.H., Zheng, C., (2007). Characteristics of hemicellulose, cellulose and lignin pyrolysis. Fuel, 86: 1781-1788.

[28] Johar, N., Ahmad, I., and Dufresne, A. (2012). "Extraction, preparation and characterization of cellulose fibre and nanocrystals from rice husk," Industrial Crops and Products 37(1), 93-99. 


\section{International Journal of Science and Research (IJSR) \\ ISSN (Online): 2319-7064}

Index Copernicus Value (2015): 78.96 | Impact Factor (2015): 6.391

[29] Reddy, K.O, Maheswari, C.U, Reddy DJP, Rajulu AV. (2009). Thermal properties of napier grass fibre. Materials letters, 63: 2390-2392.

[30] Rajulu, A.V., Rao, G.B., Rao, B.R.P, Reddy, A.M., He, J., Zhang, J., (2002). Properties of ligno- cellulose fibre hildegardia. Journal of Applied Polymer Science, 84: 2216-2221.

\section{Author Profile}

Prof. (Dr.) M. D. Teli, a Fellow of CSIR-CNRS (France), Maharashtra Academy of Science, Honorary F.T.A and Shiksha Ratna, has guided 120 Master's and Doctoral students with over 370 publications/conference presentations and edited 25 books. He is an Independent Director of Siyaram Silk Mills, Chairman of Editorial Board of JTA and a Managing Trustee of Baha'i Lotus Temple, Delhi.

Mr. Akshay C. Jadhav has completed his Msc in Textile chemistry. Currently he is pursuing Ph.D. at ICT with specialization in modifications of natural fibres to improve their performance enhancement in different fields of textiles. 